Article

\title{
Modified Three-Dimensional Jet Indices and Their Application to East Asia
}

\author{
Haishan $\mathrm{Li}^{1,2}, \mathrm{Ke}$ Fan ${ }^{1,2}, * \mathbb{0}$, Zhiqing $\mathrm{Xu}^{3}$ and Hua $\mathrm{Li}^{1}$ \\ 1 Nansen-Zhu International Research Centre, Institute of Atmospheric Physics, Chinese Academy of Sciences, \\ Beijing 100029, China; lihaishan@mail.iap.ac.cn (H.L.); lihua@mail.iap.ac.cn (H.L.) \\ 2 University of the Chinese Academy of Sciences, Beijing 100029, China \\ 3 Climate Change Research Center, Chinese Academy of Sciences, Beijing 100029, China; xuzq@mail.iap.ac.cn \\ * Correspondence: fanke@mail.iap.ac.cn; Tel.: +86-10-82995322
}

Received: 25 October 2019; Accepted: 30 November 2019; Published: 4 December 2019

\begin{abstract}
A set of three-dimensional jet indices (jet speed index, jet pressure index, jet latitude index) has been proposed in previous literature to describe the variation of jet streams in both the horizontal and vertical direction. We refer to these indices at the ' $A C^{\prime}$ ' indices, after the names of the researchers involved. However, the physical meaning of the AC indices and the relationship between AC indices and climate systems are not fully understood. Further study is still needed for applying the indices in East Asia $\left(70^{\circ}-140^{\circ} \mathrm{E}\right)$. In this study, based on the understanding of the physical meaning of the $\mathrm{AC}$ indices, latitudinal ranges of East Asian jet streams are determined, and a set of modified AC indices is proposed. Based on the modified AC indices, the linear trends in East Asian jet streams are studied, and the relationship between East Asian jet streams and the climate is researched. The results show that the jet speed index corresponds to the meridional temperature gradient (MTG) of the middle to upper troposphere (500-200 hPa); the jet pressure index corresponds to the pressure level at which the MTG equals zero; and the jet latitude reflects the meridional MTG distribution. The latitudinal ranges of jet streams are determined based on the meridional profiles of climatological zonal-mean zonal winds. Within such a latitudinal range, the climatological zonal-mean zonal winds between 400 and $100 \mathrm{hPa}$ are only westerly, and the maximum wind speed in the vertical direction at every latitude appears between 400 and $100 \mathrm{hPa}$. The jet streams can be further classified according to the features of the profiles. For East Asia $\left(70^{\circ}-140^{\circ} \mathrm{E}\right)$, jet streams can be classified into winter subtropical jet streams $\left(15^{\circ}-47.5^{\circ} \mathrm{N}\right)$, summer subtropical jet streams $\left(27.5^{\circ}-60^{\circ} \mathrm{N}\right)$, and summer polar front jet streams $\left(60^{\circ}-87.5^{\circ} \mathrm{N}\right)$. The classification of jet streams can be supported by their correspondence to the distribution of tropospheric baroclinicity. A set of modified AC indices can be acquired by using the new ranges of East Asian jet streams in the definition of the original AC indices. Descriptions of jet streams using the modified AC indices are more in accordance with the distributional features of the climatological zonal winds over East Asia, and the physical meanings of the modified AC indices are more definite than the original indices. Using the modified AC indices, we find a significant weakening trend in the strength of the summer subtropical jet stream $(-0.13 \mathrm{~m} / \mathrm{s} / 10 \mathrm{yr})$ and a significant northward shift of the winter subtropical jet stream $\left(0.22^{\circ} / 10 \mathrm{yr}\right)$, and the possible reasons for these trends are studied. Finally, the relationships of East Asian jet streams in winter and summer with atmospheric circulation, temperature, and precipitation are also investigated in this study.
\end{abstract}

Keywords: modified three-dimensional jet index; meridional temperature gradient; East Asia jet streams; subtropical and polar front jet streams; climatic characteristics 


\section{Introduction}

Jet streams are bands of high-speed winds near the tropopause, and are crucial parts of the atmospheric circulation. They are classified into two different types: subtropical jet streams and polar-front jet streams. Subtropical jets are driven by angular momentum transport from the tropics and are centered at the poleward boundaries of the Hadley cell, while polar-front jets are driven by baroclinic eddies and are associated with weather and climate events, such as precipitation and cold wave processes [1,2]. Therefore, it is of important scientific significance to study how to characterize jet streams and their relationships with weather and climate systems. However, it is difficult to clearly identify the boundaries of jet streams, especially in the Northern Hemisphere $(\mathrm{NH})$, for jet streams always show noticeable variation and discontinuity in their spatial structures.

Traditionally, researchers have used the maximum wind speed on a selected near-tropopause pressure surface and its location to describe a jet stream. For example, Yang et al. [3] defined the winter East Asia jet stream (EAJS) index as the area-averaged $200 \mathrm{hPa}$ zonal wind in the region of $\left(30^{\circ}-35^{\circ} \mathrm{N}\right.$, $130^{\circ}-160^{\circ} \mathrm{E}$ ), within which all maxima of the EAJS appeared during 1968 to 1999 . Using this index, they studied the interannual variability of the EAJS and its relationship with El Niño-Southern Oscillation (ENSO) and the extratropical North Pacific sea surface temperate (SST). Barton and Ellis [4] studied the winter North Pacific jet stream in the domain of $\left(0^{\circ}-80^{\circ} \mathrm{N}, 110^{\circ} \mathrm{E}-110^{\circ} \mathrm{W}\right)$, and defined the strength of the jet stream at a particular longitude as the strongest $300 \mathrm{hPa}$ wind within the north-south extent of the domain, and the latitudinal position of the jet stream as the latitude of the wind maximum. Based on this definition, the climatology of the jet stream for the period during 1949 to 2005 was given and a significant positive linear trend in the wind speed of the jet stream was identified. Zhang et al. [5] and Ren et al. [6] analyzed the jet streams of East Asia $\left(20^{\circ}-70^{\circ} \mathrm{N}, 60^{\circ}-140^{\circ} \mathrm{E}\right)$. They defined a grid point as a jet center when the $300 \mathrm{hPa}$ wind speed at this point was greater than $30 \mathrm{~m} / \mathrm{s}$ and the wind speed is a local wind maximum; and by applying this identification approach to the daily $300 \mathrm{hPa}$ wind speed fields of East Asia in winters and summers from 1961 to 2000, the distributions of jet occurrence numbers in the two seasons were presented. Zhang et al. [5] concluded that, in winter, two regions with large jet occurrence numbers exist over East Asia, on the northern and southern sides of the Tibetan Plateau, corresponding to the subtropical jet stream and temperate jet, respectively; while in summer, the subtropical jet stream occurs most frequently along $40^{\circ} \mathrm{N}$ and the temperate jet stream occurs only sporadically along $60^{\circ} \mathrm{N}$.

However, Koch et al. [7] pointed that, even the seasonal mean climatologies of winds at the 200 and $300 \mathrm{hPa}$ levels have significant quantitative differences. Thus, they defined the occurrence of a jet stream event as the vertically averaged horizontal wind speed between 400 and $100 \mathrm{hPa}$ at a grid meeting a threshold criterion of $30 \mathrm{~m} / \mathrm{s}$ using six-hourly reanalysis data. Based on this definition, they determined the seasonal distributions and annual cycle of the jet-event climatology for both hemispheres. Strong and Davis $[8,9]$ also pointed out that, because of the spatiotemporal variations of the altitude of a jet stream, it may be inaccurate to capture the jet stream by a single isobaric surface. Thus, they used the so-called surface of maximum wind to track the winter jet streams of the NH using six-hourly reanalysis data. The surface of maximum wind is composed of the points of greatest wind speed (larger than $25.7 \mathrm{~m} / \mathrm{s}$ ) near the tropopause, and a jet stream core is defined as a local maximum on the surface of maximum wind along each meridian. Based on the surface of maximum wind, they showed that, from 1958 to 2007, speeds and probabilities of jet stream cores increased over $\mathrm{NH}$ midlatitudes $\left(40^{\circ}-60^{\circ} \mathrm{N}\right)$, while jet cores were weaker and less frequent polewards of $60^{\circ} \mathrm{N}$.

In order to characterize both the vertical and horizontal variation of jet streams, Archer and Caldeira [10] defined a set of indices (hereafter referred to as the 'AC indices') based on the monthly mass-weighted averaged gridded wind speed between 400 and $100 \mathrm{hPa}$, considering the three-dimensional structure of jet streams. Not only the strength and latitudinal position, but the altitude of jet streams can be described by the AC indices. The winter, summer, and annual trends of the AC indices were calculated in the period of 1979-2001 for both the $\mathrm{NH}\left(15^{\circ}-70^{\circ} \mathrm{N}\right)$ and $\mathrm{SH}$ (Southern Hemisphere) (subtropical jet stream: $40^{\circ}-15^{\circ} \mathrm{S}$; polar front jet: $70^{\circ}-40^{\circ} \mathrm{S}$ ). They showed that, 
on average, jets in both hemispheres were moving polewards; plus, in the $\mathrm{NH}$, the jets were becoming weak, while in the SH the subtropical jet was weakening but the polar front jet was strengthening.

The results of Archer and Caldeira [10] are widely referenced; however, further study is needed for the physical meaning of the AC indices. For example, Strong and Davis [11] pointed out that a jet stream should be identified as a narrow band of high speed wind exceeding a minimum threshold and varying from day to day, and that the jet stream using mass-weighted averages of monthly mean 400-100 hPa wind speed cannot be clearly related to surface weather, cyclogenesis, hurricanes, and air turbulence. Molnos et al. [12] pointed out that the algorithm used by Archer and Caldeira [10] cannot distinguish between subtropical and polar front streams in the $\mathrm{NH}$ since only one jet position is detected.

Besides, characteristics of jet streams in different regions may be smoothed when being averaged over a hemispherical scale. Thus, different studies adopt their own regions of jet streams when using the AC indices. For example, Chen et al [13] chose $40^{\circ}-65^{\circ} \mathrm{N}$ as the latitudinal range of the $\mathrm{NH}$ winter polar jet stream; Thomas and Nigam [14] used the range of $15^{\circ}-65^{\circ} \mathrm{N}$ for the $\mathrm{NH}$ winter subtropical jet stream; and Fan et al. [15] adopted the range of $\left(23^{\circ}-35^{\circ} \mathrm{N}, 100^{\circ}-150^{\circ} \mathrm{E}\right)$ for the spring jet stream of East Asia.

It should also be noted that significant seasonal variations exist in the strength, altitude, and latitude of jet streams. Taking jet streams over East Asia as a case in point, the winter maximum $200 \mathrm{hPa}$ zonal wind locates at $35^{\circ} \mathrm{N}$ and near the coast of East Asia, and is the strongest in the whole year; whereas, the summer maximum $200 \mathrm{hPa}$ zonal wind moves to the south of $45^{\circ} \mathrm{N}$ and near $90^{\circ} \mathrm{E}$, and is the weakest in the year [16]. Thus, seasonal variations in jet streams should also be considered when using the $\mathrm{AC}$ indices.

In this study, the physical meanings of the AC indices are studied, and a method is proposed to determine the latitudinal ranges of jet streams. Based on this, we modify the original AC indices to better describe the winter and summer East Asian jet streams. Linear trends of East Asian jet streams and the possible relationships between East Asian jet streams and the climate system are also studied.

Following this introduction, the data and methods used in this study are introduced in Section 2. In Section 3, the physical meanings of the AC indices are examined, the classification and latitudinal ranges of East Asian jet streams are studied, and the modified AC indices are proposed. Based on the modified AC indices, linear trends of East Asian jet streams and the relationships between East Asian jet streams and the climate system are also studied in this section. A summary and discussion are provided in Section 4.

\section{Data and Methods}

The atmospheric data used in this study included the daily and monthly-mean ERA-Interim data from the European Centre for Medium-Range Weather Forecasts (https:/www.ecmwf.int/en/ forecasts/datasets/reanalysis-datasets/era-interim) with a $2.5^{\circ}$ horizontal resolution and 37 vertically distributed pressure levels, over the period from 1979 to 2018 [17]. Precipitation data with a $2.5^{\circ}$ horizontal resolution from the Global Precipitation Climatology Project (https://www.esrl.noaa.gov/ psd/data/gridded/data.gpcp.html) during the same period were also used [18].

Wind speed index (WS), pressure index $(P)$, and latitude index (Lat) were defined by Archer and Caldeira [10] to characterize the strength, the pressure level, and the latitudinal position of a jet stream, respectively. These indices are firstly calculated at each horizontal grid point or longitude, then area-averaged over the chosen region, which is $15^{\circ}-70^{\circ} \mathrm{N}$ for the $\mathrm{NH}$ [10]. At each horizontal grid point in this region, indices are defined as follows:

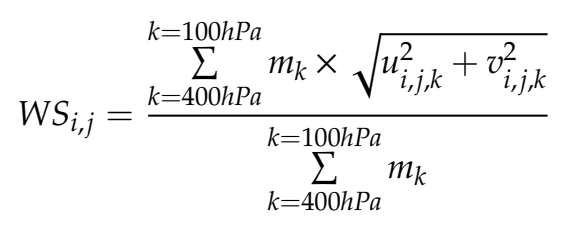




$$
\begin{array}{r}
P_{i, j}=\frac{\sum_{k=400 h P a}^{k=100 h P a}\left(m_{k} \times \sqrt{u_{i, j, k}^{2}+v_{i, j, k}^{2}}\right) \times p_{k}}{k=100 h P a} m_{k} \times \sqrt{u_{i, j, k}^{2}+v_{i, j, k}^{2}} \\
\text { Lat }_{i}=\frac{\sum_{j=1500 h P a}^{j=70 N}\left[\sum_{j=400 h P a}^{k=100 h P a}\left(m_{k} \times \sqrt{u_{i, j, k}^{2}+v_{i, j, k}^{2}}\right)\right] \times \phi_{i, j}}{\sum_{j=15 N} \sum_{k=400 h P a}\left(m_{k} \times \sqrt{u_{i, j, k}^{2}+v_{i, j, k}^{2}}\right)}
\end{array}
$$

where $u_{i, j, k}$ and $v_{i, j, k}$ are the monthly average horizontal wind components at grid $(i, j, k), m_{k}$ and $p_{k}$ are the mass and pressure at level $k$, and $\phi_{i, j}$ is the grid cell latitude; $W S_{i, j}$ is the mass-weighted average wind speed between 400 and $100 \mathrm{hPa}$ and represents the wind speed of the jet; $P_{i, j}$ is the mass-flux-weighted pressure and represents the average pressure of flows; and $L a t_{i}$ is the mass-flux-weighted latitude in the $\mathrm{NH}\left(15^{\circ}-70^{\circ} \mathrm{N}\right)$ and represents the latitude of a jet at longitude $i$.

The negative meridional temperature gradient (MTG) averaged from 500 and $200 \mathrm{hPa}(-\overline{\partial T / \partial y})$ is used in this study to represent the meridional air temperature difference of the mid-upper troposphere (500-200 hPa) [16], as shown in Equation (4):

$$
-\frac{\partial T}{\partial y}=-\frac{\int_{500 h \mathrm{~Pa}}^{200 h \mathrm{~Pa}} \frac{\partial T}{\partial y} p d p}{\int_{500 h \mathrm{~Pa}}^{200 h \mathrm{a} a} p d p}
$$

where $T$ is the air temperature and a positive (negative) $-\overline{\partial T / \partial y}$ indicates that the air temperature of the mid-upper troposphere decreases (increases) polewards. It would be more convenient to use $-\overline{\partial T / \partial y}$ than $\overline{\partial T / \partial y}$ considering that the $\mathrm{NH}-\overline{\partial T / \partial y}$ is generally positive, which corresponds to the decreasing temperature from the equator to the North Pole and to the increase of thermal wind in the vertical direction.

The midlatitude westerly jet is associated with the baroclinicity of troposphere [19]. In this study, the maximum Eady growth rate $\sigma$ is adopted to characterize the growth rate of baroclinic eddies. This parameter is defined as the linear growth rate of the most unstable baroclinic normal mode, as shown in Equation (5):

$$
\sigma=0.31 \frac{|f||\partial u / \partial z|}{N} ; N^{2}=\frac{\theta}{g} \frac{\partial \theta}{\partial z}
$$

where $f$ is the Coriolis parameter, $N$ is the Brunt-Väísälä frequency, $u$ is the zonal wind component, and $z$ is the vertical coordinate. The seasonal mean of $\sigma$ is the average of daily values. Considering that the baroclinic eddies extend through the entire depth of the troposphere, Vogit and Shaw [20] used a vertically averaged Eady growth rate:

$$
\hat{\sigma}=\frac{1}{700 h P a} \int_{200 h P a}^{900 h P a} \sigma d p
$$

In order to find the linear trends of East Asian jet streams over the whole period of 1979 to 2018, and the relationships of East Asian jet streams with atmospheric circulation, temperature and precipitation, the linear regression method was used in this study. A 9-year low-pass Fourier filter was also used to separate the interdecadal variations of the AC indices. 


\section{Results}

\subsection{Physical Meanings of the AC Indices}

Based on the principle of thermal wind, variation of wind speed in the vertical direction depends on the MTG. When the MTG is negative (positive), air temperature decreases (increases) polewards, and the westerly wind speed increases (decreases) with altitude. Thus, westerly wind speed will reach its maximum speed at the altitude (or pressure level) where the MTG is equal to zero. Therefore, based on the MTG of the mid-upper troposphere (500-200 hPa), the physical meanings of the AC indices can be understood.

In this section, we take $\mathrm{NH}$ winter as a case to illustrate the physical meanings of the AC indices. The climatological $W S_{i, j}$ in NH winter (1979-2018) is shown in Figure 1a, in which two jet stream systems can be seen over North Africa-East Asia and the eastern coast of North America, respectively. The maximum of the climatological $W S_{i, j}$ is located at $140^{\circ}$ E near the cost of East Asia and reaches up to $60 \mathrm{~m} / \mathrm{s}$. Figure $1 \mathrm{~b}$ shows the climatology of $-\overline{\partial T / \partial y}$ in NH winter (1979-2018). We can see that centers of large values of $-\overline{\partial T / \partial y}$ exist over North Africa-East Asia and the eastern coast of North America. The climatologies of $W S_{i, j}$ and $-\overline{\partial T / \partial y}$ share a similar distribution pattern, and the pattern correlation coefficient between them is 0.93 . Thus, we can conclude that, in $\mathrm{NH}$ winter, the climatological $W S_{i, j}$ corresponds to the $-\overline{\partial T / \partial y}$ of the mid-upper troposphere $(500-200 \mathrm{hPa})$.
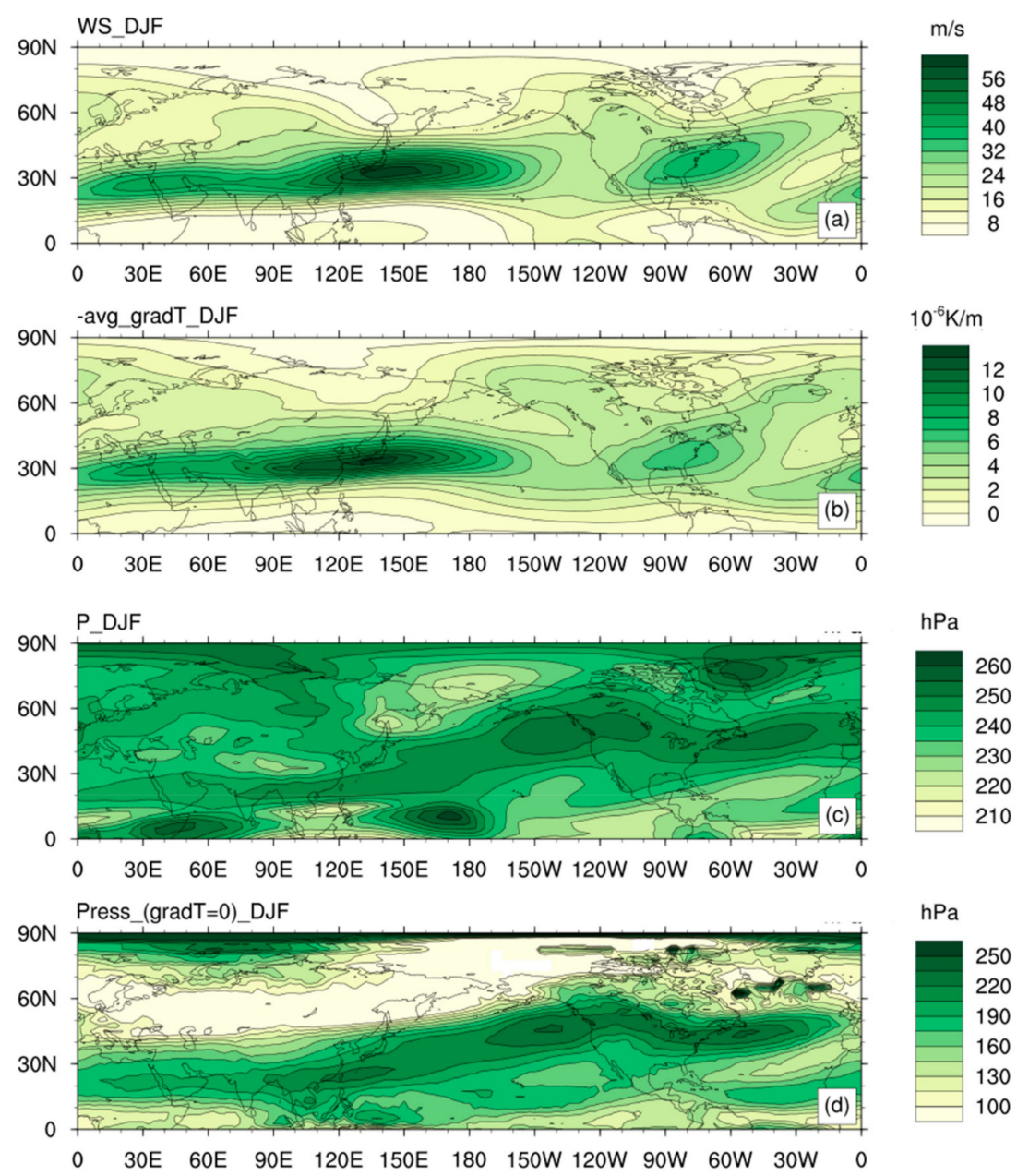

Figure 1. Climatology in winter of the Northern Hemisphere (NH) during 1979 to 2018 of (a) index $W S_{i, j}$ (units: $\left.\mathrm{m} / \mathrm{s}\right),(\mathbf{b})$ negative meridional temperature gradient (MTG) $(-\overline{\partial T / \partial y})$ averaged from 500 and $200 \mathrm{hPa}$ (units: $\mathrm{K} / \mathrm{m}),(\mathbf{c})$ index $P_{i, j}$ (units: $\mathrm{hPa}$ ), and (d) pressure at which the MTG is equal to zero (units: hPa). 
Figure 1c shows the climatological $P_{i, j}$ in NH winter (1979-2018). It can be seen that a band of high climatological $P_{i, j}$ extends from North Africa to the North Atlantic, and two centers of large values are located at $120^{\circ} \mathrm{W}$ near the western coast of North America and at $60^{\circ} \mathrm{W}$ near the North Atlantic, respectively. Figure $1 \mathrm{~d}$ shows the climatology of the pressure at which the MTG is equal to zero $\left(P_{-\partial T / \partial y=0}\right)$ in NH winter (1979-2018). We can see that a ribbon of large values of $P_{-} \partial T / \partial y=0$ extends from North Africa to East Asia, North America and the North Atlantic, and three centers of large values are located at $120^{\circ}$ E near the cost of East Asia, at $150^{\circ} \mathrm{W}$ near the western coast of North America, and at $60^{\circ} \mathrm{W}$ near the North Atlantic, respectively. The distribution of the large values of climatological $P_{-\partial T / \partial y=0}$ is similar to that of climatological $P_{i, j}$. However, the climatology of $P_{-\partial T / \partial y=0}$ north of $50^{\circ} \mathrm{N}$ differs considerably to that of $P_{i, j}$, wherein the latter is always lower than $100 \mathrm{hPa}$. The climatological pattern correlation coefficient between $P_{-\partial T / \partial y=0}$ and $P_{i, j}$ in NH winter is 0.43 . Thus, we conclude that, in NH winter, climatological $P_{i, j}$ corresponds to $P_{-\partial T / \partial y=0}$ and characterizes the pressure at which the maximum of the westerly wind (jet stream) is located.

Based on a simplification of Equation (3), we can see that, at the longitude $i$, index Lat $t_{i}$ is an average of the latitudes weighted by the corresponding $W S_{i, j}$. As mentioned above, climatological $W S_{i, j}$ corresponds to the MTG of the mid-upper troposphere (500-200 hPa). Thus, index Lat $_{i}$ corresponds to the characteristic of the distribution of the MTG at longitude $i$.

\subsection{Latitudinal Ranges and Classification of East Asian Jet Streams}

\subsubsection{Latitudinal Ranges of East Asian Jet Streams}

The latitudinal range of $\mathrm{NH}$ jet streams was determined as $15^{\circ}-70^{\circ} \mathrm{N}$ by Archer and Caldeira [10]. However, this may not be suitable for jet streams of other regions or different times. Taking winter in East Asia $\left(70^{\circ}-140^{\circ} \mathrm{E}\right)$ as an example, it can be seen in Figure 1a that a large-value center of the climatological winter $W S_{i, j}(1979-2018)$ over East Asia is located in the region $\left(15^{\circ}-40^{\circ} \mathrm{N}, 90^{\circ}-180^{\circ} \mathrm{E}\right)$. However, it can be seen in Figure 1a that the climatological $W S_{i, j}$ over East Siberia $\left(50^{\circ}-70^{\circ} \mathrm{N}\right.$, $90^{\circ}-180^{\circ} \mathrm{E}$ ) is relatively weaker than the large-value center over East Asia. Thus, in winter in East Asia, latitudes north of $50^{\circ} \mathrm{N}$ should not be included in the range of East Asian jet streams.

As mentioned above, in the vertical direction, the maximum westerly wind speed appears at the pressure level where the MTG is equal to zero within the range from the upper troposphere to the lower stratosphere (400-100 hPa). Thus, we used the following method to determine the latitudinal ranges of East Asian jet streams:

(1) Calculate the meridional profile of the climatological zonal-mean zonal wind $(U)$ of East Asia in the chosen season.

(2) Based on the meridional profile obtained in step (1), the southern and northern boundaries of a jet stream are identified following the three rules below:

(a) Southern side of the southern boundary: climatological easterly winds in the vertical range of 400-100 hPa only exist at latitudes south of the boundary;

(b) Between the southern and northern boundaries: at each latitude between these two boundaries, the maximum climatological westerly wind appears in the vertical range of 400-100 hPa;

(c) Northern side of the northern boundary: at each latitude north of the boundary, maxima of climatological westerly winds exist at the pressure lower than $100 \mathrm{hPa}$.

The meridional profiles of $U$ and MTG for winter in East Asia $\left(70^{\circ}-140^{\circ} \mathrm{E}\right)$ are given in Figure 2a. Climatological winds south of $15^{\circ} \mathrm{N}$ are mainly easterly within $400-100 \mathrm{hPa}$; in the range of $15^{\circ}-47.5^{\circ} \mathrm{N}$, the maximum of the climatological westerly wind at each latitude can be found near the pressure where the MTG is equal to 0 and within $400-100 \mathrm{hPa}$; and the maxima of westerly winds north of $47.5^{\circ} \mathrm{N}$ in the vertical direction appear at pressures lower than $100 \mathrm{hPa}$, and inversion of the MTG does 
not exist within $400-100 \mathrm{hPa}$. Thus, $15^{\circ} \mathrm{N}$ and $47.5^{\circ} \mathrm{N}$ are determined as the southern and northern boundaries for the winter East Asian jet stream, respectively. Using the same method, the latitudinal range of the summer East Asian jet stream can be determined as $27.5^{\circ}-87.5^{\circ} \mathrm{N}$ (Figure 2c).
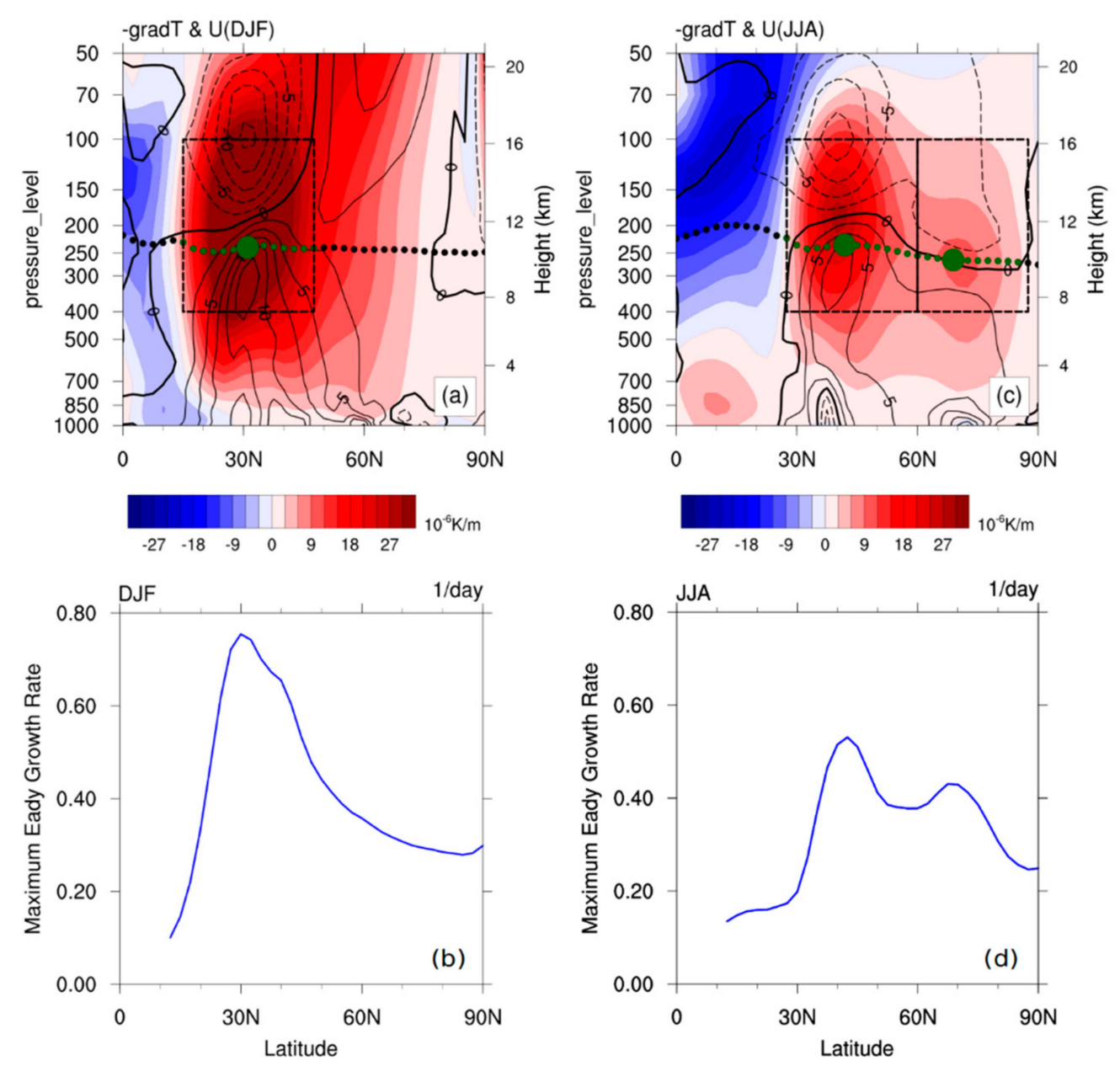

Figure 2. (a) Meridional profile of climatological zonal-mean winter MTG (shading; units: K/m), zonal winds (contours; units: $\mathrm{m} / \mathrm{s}$ ), modified index $P^{M}$ (small dots; units: hPa), and modified index Lat ${ }^{M}$ (big dots; units ${ }^{\circ} \mathrm{N}$ ) in East Asia $\left(70^{\circ}-140^{\circ} \mathrm{E}\right.$ ) during 1979 to 2018. (b) Climatological winter vertically averaged Eady growth rate during 1979 to 2018 (units: 1/day). (c,d) As in (a,b) but for summer. The dashed box in (a) shows the vertical and latitudinal ranges used to define the winter East Asian subtropical jet stream, and the two dashed boxes in (c) show the ranges used to define the summer East Asian subtropical jet stream and polar front jet stream.

\subsubsection{Classification of East Asian Jet Streams and Its Verification}

In general, jet streams are classified into two types: subtropical jet streams and polar front jet streams. In some cases, however, it is difficult to have a clear dual-jet structure $[7,21,22]$. Thus, in some studies (e.g., Archer and Caldeira [10] and Faranda et al. [23]), a single jet stream pattern is used rather than a dual pattern. In this study, based on the meridional profile of the climatological zonal-mean zonal wind, we propose a new classification of East Asian jet streams.

From the meridional profile of the climatological zonal-mean zonal wind of winter in East Asia $\left(70^{\circ}-140^{\circ} \mathrm{E}\right)$ (Figure 2a) we can see that, in the vertical range of $400-100 \mathrm{hPa}$, a large-value center of climatological westerly winds locates within the latitudinal range $15^{\circ}-47.5^{\circ} \mathrm{N}$, which suggests that the winter jet stream in this range is a subtropical jet stream [21,22]. 
Figure $2 \mathrm{c}$ is the same as Figure 2a but for summer. We can see that, in the range of East Asian summer jet streams $\left(27.5^{\circ}-87.5^{\circ} \mathrm{N}\right)$, two centers of large speed exist: the southern one is located at $\left(200 \mathrm{hPa}, 40^{\circ} \mathrm{N}\right)$ and has a stronger wind speed; the northern one is located at $\left(250 \mathrm{hPa}, 70^{\circ} \mathrm{N}\right)$ and its wind speed is weaker; and these two centers separate at $60^{\circ} \mathrm{N}$. Thus, we can conclude that two separated jet streams exist over summer in East Asia: the southern one is a subtropical jet stream and exists in the range of $27.5^{\circ}-60^{\circ} \mathrm{N}$; and the northern one is a polar front jet stream and exists in the range of $60^{\circ}-87.5^{\circ} \mathrm{N}$.

The classification of jet streams given above can be supported by the results of Lee and Kim [22]. They pointed out that, if a subtropical jet is strong enough, the primary region of the baroclinic wave growth coincides with the region of the subtropical jet, and thus a separated polar front jet does not form at latitudes much higher than the latitude of the subtropical jet stream; whereas, if the subtropical jet is weak, baroclinic wave growth takes places mainly in the baroclinic zone at a higher latitude, and then a separated polar front jet stream appears at this latitude. As the vertically averaged Eady growth rate $\hat{\sigma}$ can be used to characterize the growth of baroclinic eddies in extratropical regions [20], we can verify our classification based on the variation of $\hat{\sigma}$ in winter and summer.

Figure $2 \mathrm{~b}$ shows the climatological $\hat{\sigma}$ of winter in East Asia $\left(70^{\circ}-140^{\circ} \mathrm{E}\right)$. We can see that $\hat{\sigma}$ peaks in the range of $15^{\circ}-47.5^{\circ} \mathrm{N}$, where winter subtropical jet streams exist; while at higher latitudes, $\hat{\sigma}$ is relatively weaker. The maximum of $\hat{\sigma}$ corresponds to the winter subtropical jet stream. Westerly jet streams are related with a strong MTG according to the principle of thermal wind, and the strong MTG is related to the strong baroclinicity in this region. This agrees with Lee and Kim [22] in that, when a strong subtropical jet appears, no separated polar front jet exists at latitudes higher than the latitude of the subtropical jet stream.

Figure $2 \mathrm{~d}$ is the same as Figure $2 \mathrm{~b}$ but in summer, from which we can see that, in the mid-upper troposphere (500-200 $\mathrm{hPa}$ ), $\hat{\sigma}$ peaks in both $27.5^{\circ}-60^{\circ}$ and $60^{\circ}-87.5^{\circ} \mathrm{N}$, corresponding to the latitudinal ranges of the subtropical jet and polar front jet. We can also see that, in the range of the summer subtropical jet stream $\left(27.5^{\circ}-60^{\circ} \mathrm{N}\right), \hat{\sigma}$ is weaker in summer than in winter (Figure $2 \mathrm{~b}, \mathrm{~d}$ ), which corresponds to the relatively weaker summer subtropical jet stream; while in the range of the polar front jet stream $\left(60^{\circ}-87.5^{\circ} \mathrm{N}\right), \hat{\sigma}$ is stronger in summer, which corresponds to the separated summer polar jet stream at high latitudes. This is also in agreement with Lee and Kim [22] in that, when a weak subtropical jet stream appears, baroclinic wave growth takes places mainly at a higher latitude, and a separated polar front jet stream appears at this latitude.

\subsubsection{Modification of the AC indices for Winter and Summer East Asian Jet Streams}

Based on the latitudinal ranges of jet streams of winter and summer in East Asia $\left(70^{\circ}-140^{\circ} \mathrm{E}\right)$, the original AC indices can be further modified. In this section, the definitions of the modified AC indices for a certain jet stream are given as follows:

(1) Calculate the modified $\mathrm{AC}$ indices $\left(W S_{i, j}^{M}, P_{i, j}^{M}\right.$ and $\left.L a t_{i}^{M}\right)$ at each grid or longitude of East Asia $\left(70^{\circ}-140^{\circ} \mathrm{E}\right)$.

(a) The calculations of $W S_{i, j}^{M}$ and $P_{i, j}^{M}$ at each grid of East Asia $\left(70^{\circ}-140^{\circ} \mathrm{E}\right)$ are the same as Equations (1) and (2):

$$
\begin{gathered}
W S_{i, j}^{M}=W S_{i, j} \\
P_{i, j}^{M}=P_{i, j}
\end{gathered}
$$

(b) The calculation of $L a t_{i}^{M}$ at each longitude of East Asia $\left(70^{\circ}-140^{\circ} \mathrm{E}\right)$ is based on the latitudinal range of the studied jet stream: 


$$
\mathrm{Lat}_{i}^{\mathrm{M}}=\frac{\sum_{j=B_{\text {South }}}^{j=B_{\text {North }}}\left[\sum_{k=400 \mathrm{hPa}}^{k=100 \mathrm{hPa}}\left(m_{k} \times \sqrt{u_{i, j, k}^{2}+v_{i, j, k}^{2}}\right)\right] \times \phi_{i, j}}{\sum_{j=B_{\text {South }}} \sum_{k=400 \mathrm{PPa}}\left(m_{k} \times \sqrt{u_{i, j, k}^{2}+v_{i, j, k}^{2}}\right)}
$$

where $B_{\text {South }}$ and $B_{\text {Nouth }}$ are the southern and northern boundaries of the jet stream, respectively: for East Asian winter subtropical jet streams, $B_{\text {South }}$ and $B_{\text {Nouth }}$ are $15^{\circ}$ and $47.5^{\circ} \mathrm{N}$; for East Asian summer subtropical jet streams they are $27.5^{\circ}$ and $60^{\circ} \mathrm{N}$; and for East Asian summer polar front jet streams they are $60^{\circ}$ and $87.5^{\circ} \mathrm{N}$. The other symbols in Equation (9) are the same as in Equation (3).

(2) The modified AC indices $\left(W S_{i, j^{\prime}}^{M} P_{i, j^{\prime}}^{M}\right.$ and $\left.L a t_{i}^{M}\right)$ for the studied jet stream are calculated as the area averages of the modified indices on grids or longitudes $\left(W S_{i, j^{\prime}}^{M} P_{i, j^{\prime}}^{M}\right.$ and $\left.L a t_{i}^{M}\right)$ over its region:

$$
\begin{gathered}
W S^{M}=\left\langle W S_{i, j}^{M}\right\rangle \quad \begin{array}{c}
i=70^{\circ} \sim 140^{\circ} \mathrm{E} \\
j=B_{\text {South }} \sim B_{\text {North }}
\end{array} \\
P^{M}=\left\langle P_{i, j}^{M}\right\rangle \quad \begin{array}{c}
i=70^{\circ} \sim 140^{\circ} \mathrm{E} \\
j=B_{\text {South }} \sim B_{\text {North }}
\end{array} \\
\text { Lat }^{M}=\left\langle\text { Lat }_{i}^{M}\right\rangle_{i=70^{\circ} \sim 140^{\circ} \mathrm{E}}
\end{gathered}
$$

where the brackets $\langle\bullet\rangle$ represent the area-average of a specified quantity and the subscript specifies the area. For East Asian jet streams, $B_{\text {South }}$ and $B_{\text {Nouth }}$ are the same as in Equation (9).

3.2.4. Comparison of the Performance in Describing East Asian Jet Streams between the Original and Modified AC Indices

The original AC indices can also be conformed in East Asia $\left(70^{\circ}-140^{\circ}\right.$ E) to describe East Asian jet streams. The time-mean original and modified AC indices over 1979-2018 are compared in this section. In the text below, the modified AC indices for the winter subtropical jet stream, the summer subtropical jet stream, and the summer polar front jet stream are denoted by the subscripts SJ_DJF, SJ_JJA, and PJ_JJA, respectively.

In winter, the modified AC indices are used to describe the subtropical jet stream $\left(15^{\circ}-47.5^{\circ} \mathrm{N}\right)$. The time-mean $W S$ and $W S_{S S_{-} D J F}^{M}$ are 23.9 and $31.9 \mathrm{~m} / \mathrm{s}$; the time-mean $P$ and $P_{\text {SI_DJF }}^{M}$ are 240.6 and $239.9 \mathrm{hPa}$; and the time-mean Lat and $L a t_{S J_{-} D J F}^{M}$ are $39.1^{\circ}$ and $31.06^{\circ} \mathrm{N}$. The different latitudinal ranges may lead to the differences between the time-mean speed indices ( $W S$ and $W S_{S J_{-} D J F}^{M}$ ) and between the time-mean latitude indices (Lat and $L a t_{S J \_D J F}^{M}$ ). In Figure 2a, we can see that climatological zonal winds higher than $47.5^{\circ} \mathrm{N}$ are weaker than winds in the range of $15^{\circ}-47.5^{\circ} \mathrm{N}$, and the pressure where the maximum wind speed exists is lower than $100 \mathrm{hPa}$. Thus, it can be concluded that, in winter in East Asia, the westerly winds north of $47.5^{\circ} \mathrm{N}$ are not jet streams. The wider latitudinal range $\left(15^{\circ}-70^{\circ} \mathrm{N}\right)$ will lead to a weaker wind speed index WS and a higher latitudinal index Lat. The values of the time-mean pressure indices $P$ and $P_{S J_{-} D J F}^{M}$ are similar; however, it can be seen from Figure 2a that, at latitudes north of $47.5^{\circ} \mathrm{N}$, distinctions between $P$ and $P_{-\partial T / \partial y=0}$ are large, which means that only in the latitudinal range of a jet stream can index $P$ represent the vertical location of jet streams and maintain its physical meaning.

In summer, two East Asian jet streams are described by the modified AC indices: the summer subtropical jet stream (SJ_JJA, $27.5^{\circ}-60^{\circ} \mathrm{N}$ ) and the summer polar jet stream (PJ_JJA, $60^{\circ}-87.5^{\circ} \mathrm{N}$ ). The time-mean $W S, W S_{S_{J_{-} J J A^{\prime}}^{M}}$ and $W S_{P_{-} J J A}^{M}$ are $10.8,13.6$, and $8.4 \mathrm{~m} / \mathrm{s}$; the time-mean $P, P_{\text {SIJJJA }^{\prime}}^{M}$ and

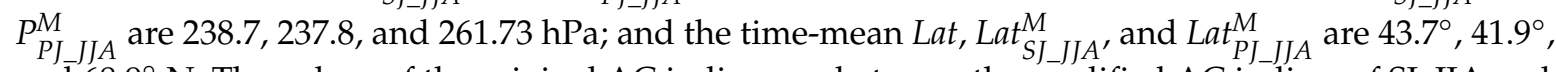
and $68.9^{\circ} \mathrm{N}$. The values of the original AC indices are between the modified AC indices of SJ_JJA and 
PJ_JJA. However, in Figure $2 \mathrm{c}$ we can see that the latitudinal range $15^{\circ}-70^{\circ} \mathrm{N}$ is too large for SJ_JJA since the climatological easterly winds in the range of $15^{\circ}-27.5^{\circ} \mathrm{N}$ are included, and too small for PJ_JJA since the center of high speed north of $70^{\circ} \mathrm{N}$ is excluded. Thus, the latitudinal range $15^{\circ}-70^{\circ} \mathrm{N}$ is unsuitable for the East Asian summer jet streams.

Therefore, we can conclude that the descriptions of jet streams using the modified AC indices are more in accordance with the distributional feature of the climatological zonal winds of East Asia, and the physical meanings of the modified AC indices are more definite than the original indices.

\subsection{Linear Trends and Nonlinear Variations of East Asian Jet Streams in Winter and Summer Based on the Modified AC Indices}

Based on the modified AC indices, we further analyzed the linear trends of the winter subtropical jet stream (SJ_DJF), summer subtropical jet stream (SJ_JJA), and summer polar front jet stream (PJ_JJA) of East Asia $\left(70^{\circ}-140^{\circ} \mathrm{E}\right)$ during 1979 and 2018 by linear regression and the nonlinear variations of the modified AC indices by using a 9-year low-pass Fourier filter, to illustrate the interannual and interdecadal variations of the jet indices. Additionally, the linear trends are mainly discussed below.

Time series, filtered time series, and linear trends of each modified $\mathrm{AC}$ index $\left(W S^{M}, P^{M}\right.$, and $\left.L a t^{M}\right)$ of these three jet streams during 1979 to 2018 are given in Figure 3.

In Figure 3a,d,g, it can be seen that, during 1979 to 2018, the trend in WS ${ }^{M}$ of SJ_JJA is $-0.13 \mathrm{~m} / \mathrm{s} / 10 \mathrm{yr}$, and is significant at the $90 \%$ confidence level, which means that the wind speed of SJ_JJA is weakening; and the linear trends in $W S^{M}$ of SJ_DJF and PJ_JJA are 0.06 and $0.17 \mathrm{~m} / \mathrm{s} / 10$ $\mathrm{yr}$, both of which are not significant at the $90 \%$ confidence level, which means that both have a weak strengthening trend. Besides, although the linear trend in the WS ${ }^{M}$ of PJ_JJA is relatively large, its variation (standard deviation) is also the largest $(0.92 \mathrm{~m} / \mathrm{s})$.

In Figure 3b,e,h, we can see that, during 1979 to 2018, the linear trends in $P^{M}$ of SJ_DJF, SJ_JJA, and PJ_JJA are $-0.20,-0.24$, and $-0.13 \mathrm{hPa} / 10 \mathrm{yr}$, respectively, which means that the pressures of all these jet streams are lowering slightly, albeit not significantly at the $90 \%$ confidence level. Among the three jet streams, the trend of PJ_JJA is the weakest, but its variation (standard deviation) is the largest $(2.09 \mathrm{hPa})$.

Furthermore, in Figure 3c,f,i, we can see that, during 1979 to 2018, the linear trends in $\mathrm{Lat}^{\mathrm{M}}$ of SJ_DJF and SJ_JJA are $0.22^{\circ} / 10 \mathrm{yr}$ and $0.09^{\circ} / 10 \mathrm{yr}$, respectively, which means that both SJ_DJF and SJ_JJA are shifting polewards. The trend of SJ_DJF is significant at the $90 \%$ confidence level. The linear trend in $L a t^{M}$ of PJ_JJA is $-0.14^{\circ} / 10 \mathrm{yr}$, which means that PJ_JJA has a trend of moving equatorwards, albeit not significantly at the $90 \%$ confidence level. Besides, the variation in Lat ${ }^{M}$ of PJ_JJA is the largest among the three jet streams $\left(0.87^{\circ}\right)$.

The results given above show that, during 1979 to 2018, SJ_DJF has a significant trend of shifting polewards, and the wind speed of SJ_JJA has a significant weakening trend. As mentioned, the characteristics of jet streams described by the modified AC indices can be related to the MTG of the mid-upper troposphere (500-200 hPa), and therefore the trends shown in Figure 3c, d might be attributable to the change in the winter and summer troposphere MTG of East Asia $\left(70^{\circ}-140^{\circ} \mathrm{E}\right)$.

The poleward-shifting trend in SJ_DJF might be related to the change in the mid-upper troposphere MTG of winter in East Asia. Figure 4a shows the meridional profiles of the climatology and the linear trend of the zonal-mean MTG of winter in East Asia $\left(70-140^{\circ}\right.$ E) during 1979 to 2018. In Figure 4a we can see a significant strengthening trend in the zonal-mean MTG between 500 and $200 \mathrm{hPa}$ within $30^{\circ}-50^{\circ} \mathrm{N}$; however, within $15^{\circ}-30^{\circ} \mathrm{N}$, a mainly weakening trend is apparent. Figure $4 \mathrm{c}$ is the same as Figure 4a but for zonal-mean zonal wind. In Figure 4c we can see that, corresponding to the trends in the zonal-mean MTG (Figure 4a), the speeds of westerly winds north of SJ_DJF $\left(30^{\circ}-50^{\circ} \mathrm{N}\right.$, $400-100 \mathrm{hPa})$ show a significant strengthening trend; while on the south side $\left(15^{\circ}-30^{\circ} \mathrm{N}, 400-100 \mathrm{hPa}\right)$, westerly wind speeds show a mainly weakening trend. These opposite trends of westerly winds on the north and south sides of SJ_DJF may result in a trend of moving polewards. 

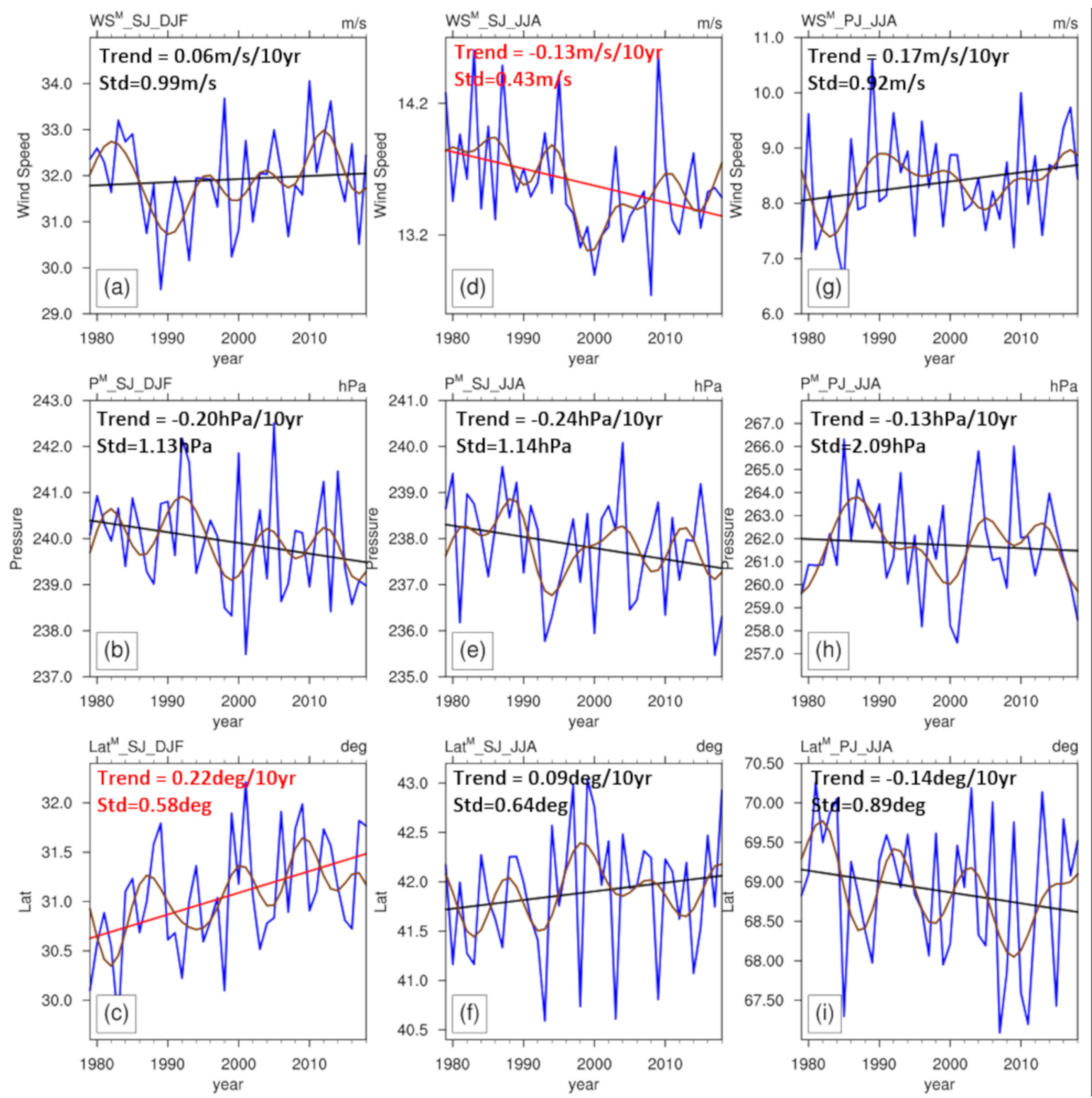

Figure 3. Time series (blue line), filtered time series by a 9-year low pass Fourier filter (brown line) and linear trend (black or red line, where the red line indicates the trend is significant at the $90 \%$ confidence level, as estimated by a Student's $t$-test) of (a) index $W S^{M}$ (units: $\mathrm{m} / \mathrm{s}$ ), (b) index $P^{M}$ (units: hPa), and (c) index $\mathrm{Lat}^{\mathrm{M}}$ (units: ${ }^{\circ} \mathrm{N}$ ) with respect to the subtropical jet in winter (DJF) over East Asia $\left(70^{\circ}-140^{\circ} \mathrm{E}\right)$. Panels $(\mathbf{d}, \mathbf{e}, \mathbf{f})$ and $(\mathbf{g}, \mathbf{h}, \mathbf{i})$ are the same as $(\mathbf{a}, \mathbf{b}, \mathbf{c})$, but for the summer (JJA) subtropical jet and summer (JJA) polar front jet over East Asia $\left(70^{\circ}-140^{\circ} \mathrm{E}\right)$, respectively.

The weakening trend in wind speed of SJ_JJA may also be related to the change of the MTG in the mid-upper troposphere $(500-200 \mathrm{hPa})$ of East Asia $\left(70^{\circ}-140^{\circ} \mathrm{E}\right)$. Figure $4 \mathrm{~b}, \mathrm{~d}$ is the same as Figure $4 \mathrm{a}, \mathrm{c}$, but in summer. In Figure $4 \mathrm{~b}$, the zonal-mean MTG between 500 and $200 \mathrm{hPa}$ within $30^{\circ}-50^{\circ} \mathrm{N}$ shows a weakening trend; and in Figure 4c, corresponding to the trend of the zonal-mean MTG, the speeds of westerly winds in a similar latitudinal range are also weakening, which may result in the weakening trend in wind speed of SJ_JJA. 

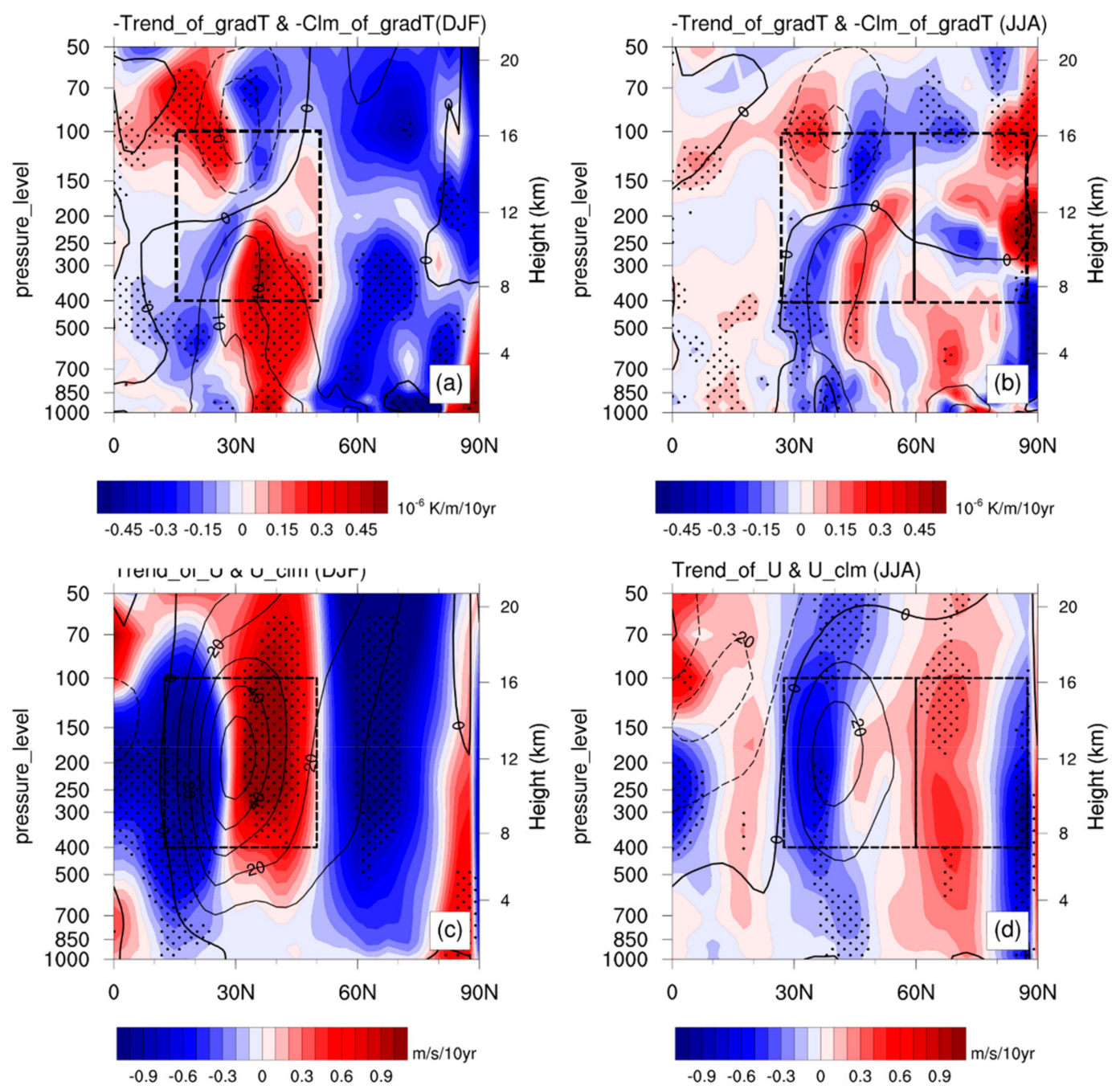

Figure 4. Meridional profile of the climatological zonal mean of (a) negative MTG (contours; units: $\mathrm{K} / \mathrm{m}$ ) and (c) its linear trend for winter in East Asia $\left(70^{\circ}-140^{\circ} \mathrm{E}\right)$ during 1979 to 2018. (b,d) As in (a,c) but in summer. The dashed box in $(\mathbf{a}, \mathbf{c})$ shows the region used to define the jet indices of the subtropical jet of winter in East Asia, and the dashed boxes in $(\mathbf{b}, \mathbf{d})$ show the regions used to define the jet indices of the subtropical jet and polar front jet of summer in East Asia, respectively. Trends significant at the 95\% confidence level are denoted with dots, as estimated by a Student's $t$-test.

\subsection{Relationship between the East Asian Climate System and Jet Streams}

In order to further study the relationship between the climate system and jet streams of East Asia $\left(70^{\circ}-140^{\circ} \mathrm{E}\right)$, the regressions of the $850 \mathrm{hPa}$ wind field and surface air temperature onto the detrended series of $W S^{M}, P^{M}$, and $L a t^{M}$ are given in Figure 5. Figure 6 is similar to Figure 5 but for precipitation and the $850 \mathrm{hPa}$ wind field.

The increase in the strength of SJ_DJF corresponds to the anomalies of low-level westerly winds over South Asia $\left(15^{\circ}-30^{\circ} \mathrm{N}\right)$ and the anomalies of northeasterly winds over Siberia, where the cold and dry air brought by the latter leads to a cooling in Siberia and North China (Figure 5a) and a reduction of precipitation over the east of the Urals (Figure 6a). The increase in the pressure of SJ_DJF corresponds to the anomalies of low-level easterly winds over North Asia $\left(30^{\circ}-50^{\circ} \mathrm{N}\right)$ and the cooling in South China and Indochina (Figure $5 b$ ). However, the association is weak between the pressure of SJ_DJF and precipitation (Figure 6b). Additionally, the poleward shift of SJ_DJF corresponds to the anomalous anticyclonic circulation over the south of East Asia $\left(15^{\circ}-30^{\circ} \mathrm{N}\right)$, and the warm advection on the western side of the anticyclone is conducive to the warming over Myanmar (Figure 5c), while under the anomalous anticyclone, a reduction of precipitation exists over Southeast China (Figure 6c). 


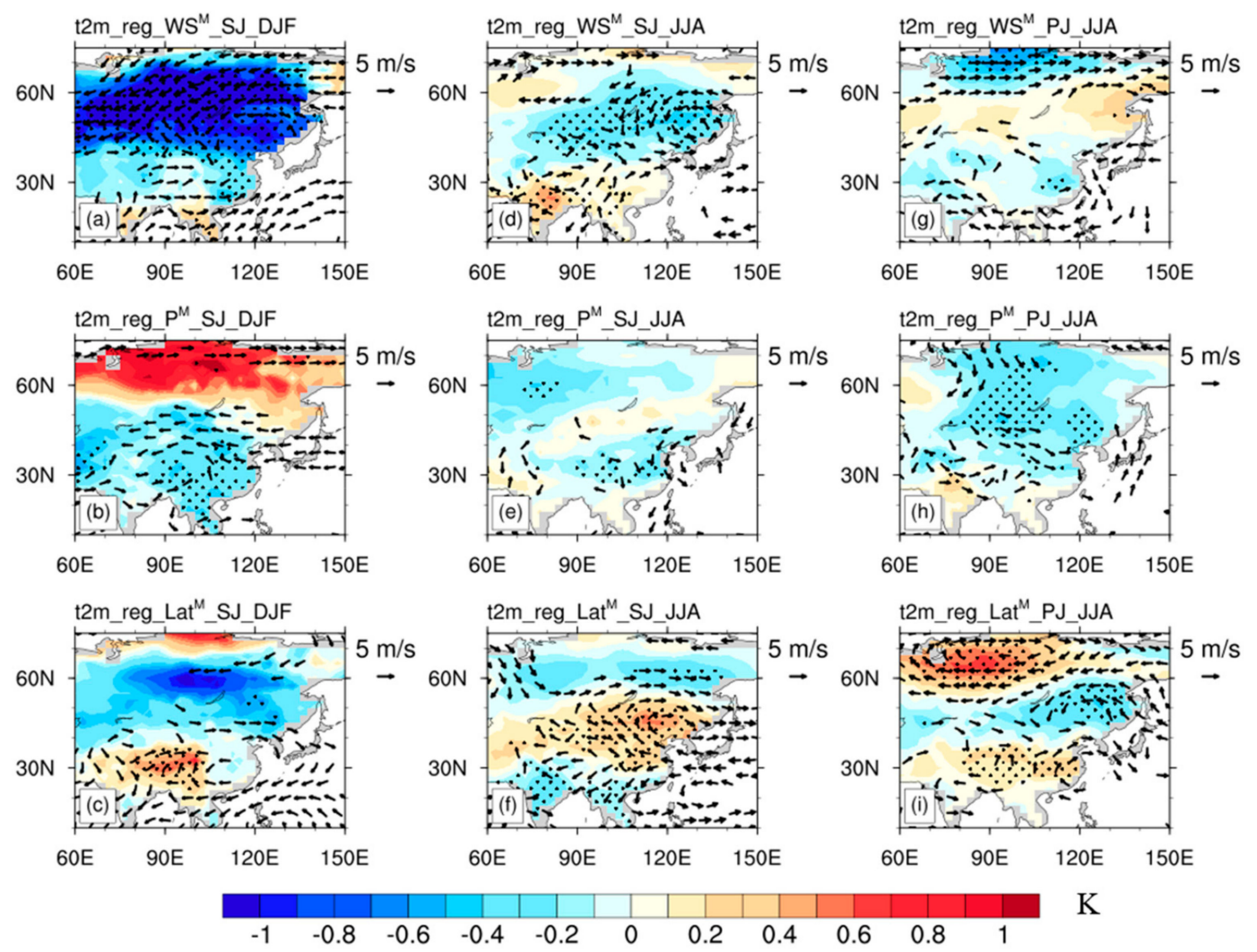

Figure 5. (a-c) Regressions of surface air temperature (t2m) (shading; units: $\mathrm{K}$ ) and $850 \mathrm{hPa}$ winds (vectors; units: $\mathrm{m} / \mathrm{s}$ ) in winter onto the detrended modified $\mathrm{AC}$ indices $\left(W S^{M}, P^{M}\right.$, and $L a t^{M}$ ) of SJ_DJF. $(\mathbf{d}-\mathbf{f})$ As in $(\mathbf{a}-\mathbf{c})$ but of SJ_JJA and in summer. $(\mathbf{g}-\mathbf{i})$ As in $(\mathbf{a}-\mathbf{c})$ but of PJ_JJA and in summer. Trends significant at the $95 \%$ confidence level are denoted by dots, and vectors represent the wind trends significant at the $90 \%$ confidence level, as estimated by a Student's $t$-test.

The increase in the strength of SJ_JJA corresponds to the anomalous cyclonic circulation over Northeast China, anomalous northeasterly winds over Mongolia, and anomalous westerly winds over North China (Figure 5d). This anomalous cyclone leads to a cooling and increase in precipitation over Mongolia and Northeast China (Figures $5 \mathrm{~d}$ and $6 \mathrm{~d}$ ). The increase in the pressure of SJ_JJA corresponds to the anomalies of northeasterly winds from the middle and lower reaches of Yangtze River to Japan. The cold advection brought by the anomalous northeasterly winds leads to a cooling in these areas (Figure 5e). Meanwhile, the association between SJ_JJA and precipitation is weak (Figure 6e); plus, the poleward shift of SJ_JJA corresponds to the anomalous anticyclonic circulation over the north of East Asia $\left(30^{\circ}-60^{\circ} \mathrm{N}\right)$ (Figure $5 \mathrm{f}$ ), which is conducive to a cooling (Figure $5 \mathrm{f}$ ) and reduced precipitation (Figure 6f) over North China.

The increase in the strength of PJ_JJA corresponds to the anomalies of westerly winds over North Siberia. The cold advection and moisture transport brought by the anomalous westerly winds are conducive for the cooling (Figure $5 \mathrm{~g}$ ) and the increase in precipitation (Figure $6 \mathrm{~g}$ ) over North Siberia. The increase in the pressure of PJ_JJA corresponds to the anomalies of northerly winds from Siberia to North China and the anomalies of southerly winds near Japan. The cold advection brought by the former causes a cooling over Mongolia and Northeast China (Figure 5h), with the warm and moist air brought by the latter being conducive to the weak increase in precipitation over Northeast China (Figure 6h). Furthermore, the poleward shift of PJ_JJA corresponds to the anomalous anticyclonic circulation over Siberia and the anomalous cyclonic circulation over Northeast China (Figure 5i). The former is conducive to the warming (Figure 5i) and reduced precipitation (Figure 6i) over Siberia, and the latter corresponds to the cooling and increased precipitation over Northeast China. 

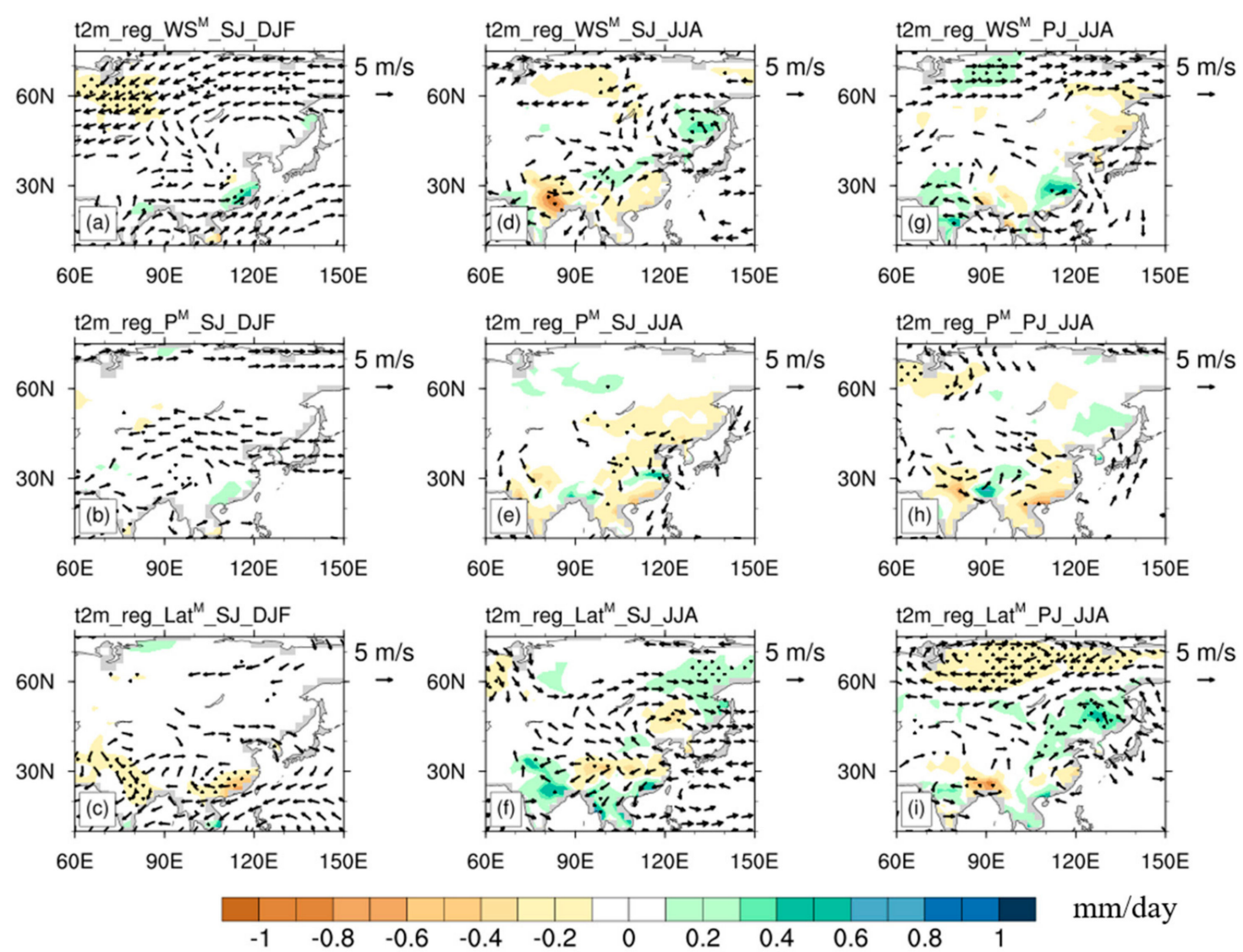

Figure 6. (a-c) Regressions of precipitation (shading; units: $\mathrm{mm} /$ day) and $850 \mathrm{hPa}$ winds (vectors, $\mathrm{m} / \mathrm{s}$ ) in winter onto the detrended modified AC indices $\left(W S^{M}, P^{M}\right.$, and $\left.L a t^{M}\right)$ of SJ_DJF. (d-f) As in (a-c) but of SJ_JJA and in summer. (g-i) As in (a-c) but of PJ_JJA and in summer. Trends significant at the $95 \%$ confidence level are denoted by dots, and vectors represent the wind trends significant at the $90 \%$ confidence level, as estimated by a Student's $t$-test.

\section{Conclusions and Discussion}

It is difficult to clearly describe jet streams in the $\mathrm{NH}$ because of the noticeable variations and discontinuity in their spatial structure. Traditionally, researchers have tended to describe jet streams using the zonal winds on a single pressure surface. A set of jet stream indices (jet speed index, jet pressure index, jet latitude index) were defined by Archer and Caldeira [10] based on the mass-weighted average of gridded wind speed between 400 and $100 \mathrm{hPa}$ to describe the variation of jet streams in both the horizontal and vertical direction. However, the physical meanings of these AC indices and their relationships with weather and climate systems are not fully understood; it is still not clear how to determine the latitudinal range of jet streams used in the AC indices and further study is needed for their applicability in East Asia. Thus, in this study, the physical meanings of the AC indices were examined, the classification and descriptions of winter and summer East Asian jet streams were studied, and their latitudinal ranges were given. A set of modified indices were proposed by using the new ranges of East Asian jet streams in the definition of the original AC indices. Based on the modified $\mathrm{AC}$ indices, the linear trends in the jet streams and the relationships between East Asian jet streams and the climate were investigated. The main results can be summarized as follows:

In terms of the physical meanings of the AC indices, the jet speed index (WS) corresponds to the MTG of the mid-upper troposphere (500-200 hPa); the jet pressure index $(P)$ corresponds to the pressure at which the MGT is equal to zero; and the jet latitude index (Lat) reflects the meridional distribution of the MTG. 
The latitudinal ranges of jet streams are determined based on the meridional profiles of climatological zonal-mean zonal winds. Within such a latitudinal range, the climatological zonal-mean zonal winds between 400 and $100 \mathrm{hPa}$ are only westerly, and the maximum wind speed in the vertical direction at every latitude appears between 400 and $100 \mathrm{hPa}$. The jet streams can be further classified according to the features of the profiles. For East Asia $\left(70^{\circ}-140^{\circ} \mathrm{E}\right)$, jet streams can be classified into winter subtropical jet streams $\left(15^{\circ}-47.5^{\circ} \mathrm{N}\right)$, summer subtropical jet streams $\left(27.5^{\circ}-60^{\circ} \mathrm{N}\right)$ and summer polar front jet streams $\left(60^{\circ}-87.5^{\circ} \mathrm{N}\right)$. The classification of jet streams can be supported by their correspondence to the distribution of tropospheric baroclinicity.

A set of modified AC indices (including the modified wind speed index $W S^{M}$, the modified pressure index $P^{M}$, and the modified latitude index $L a t^{M}$ ) can be obtained by applying the new latitudinal ranges of East Asian jet streams in the definition of the original AC indices given by Archer and Caldeira [10]. Descriptions of jet streams using the modified AC indices are more in accordance with the distributional feature of the climatological zonal winds of East Asia, and the physical meanings of the modified AC indices are more definite than the original indices.

With respect to the linear treads of winter and summer East Asian jet streams, based on the variation of indices $W S^{M}$ and $L a t^{M}$ during 1979 to 2018, we find a significant weakening trend in the strength of the East Asian summer subtropical jet stream $(-0.13 \mathrm{~m} / \mathrm{s} / 10 \mathrm{yr})$ and a significant northward shift of the East Asian winter subtropical jet stream $\left(0.22^{\circ} / 10 \mathrm{yr}\right)$. These two significant trends might be related to the change in the winter and summer MTG in the mid-upper troposphere (500-200 hPa) during 1979 to 2018.

Regarding the relationships between East Asian jet streams and the atmospheric circulation, temperature and precipitation, the variations of jet streams are always accompanied by change in the lower-level circulation, which can further influence the temperature and precipitation. The main results in this respect can be given as follows:

(1) For the winter subtropical jet stream (SJ_DJF), the increase in strength corresponds to the anomalies of low-level westerly winds over South Asia $\left(15^{\circ}-30^{\circ} \mathrm{N}\right)$ and anomalies of northeasterly winds over Siberia, with the cold and dry air brought by the latter leading to a cooling over Siberia and North China; the increase in the pressure of SJ_DJF corresponds to the anomalies of low-level easterly winds over North Asia $\left(30^{\circ}-50^{\circ} \mathrm{N}\right)$ and the cooling over South China and Indochina; and the poleward shift of SJ_DJF corresponds to the anomalous anticyclonic circulation over the south of East Asia $\left(15^{\circ}-30^{\circ} \mathrm{N}\right)$, and under the anomalous anticyclone, precipitation declines over Southeast China.

(2) For the summer subtropical jet stream (SJ_JJA), the increase in strength corresponds to the anomalous cyclonic circulation from Mongolia to Northeast China, which leads to a cooling and increased precipitation in these areas; the increase in the pressure of SJ_JJA corresponds to the anomalies of northeasterly winds from the middle and lower reaches of the Yangtze River to Japan, which leads to a cooling in these areas; and the poleward shift of SJ_JJA corresponds to the anomalous anticyclonic circulation over Northeast Asia $\left(30^{\circ}-60^{\circ} \mathrm{N}\right)$, which is conducive to a cooling and reduced precipitation over North China.

(3) For the summer polar jet stream, the increase in strength corresponds to the anomalies of westerly winds over North Siberia, which are conducive to the cooling and increased precipitation in that region; the increase in pressure corresponds to the anomalies of northerly winds from Siberia to North China and the anomalies of southerly winds near Japan, with the former causing a cooling over Mongolia and Northeast China and the latter being conducive to the weak increase in precipitation over Northeast China; and the poleward shift of PJ_JJA corresponds to the anomalous anticyclonic circulation over Siberia and the anomalous cyclonic circulation over Northeast China, with the former being conducive to the warming and reduced precipitation over Siberia, and the latter corresponding to the cooling and increased precipitation over Northeast China. 
Author Contributions: Writing—original draft, H.L. (Haishan Li); Writing—review and editing, K.F., Z.X. and H.L. (Hua Li).

Funding: This research was jointly supported by the National Natural Science Foundation of China (Grants 41730964 and 41575079) and the National Key R\&D Program of China (2017YFA0603802).

Conflicts of Interest: The authors declare no conflict of interest.

\section{References}

1. Ding, Y.H. Advanced Synoptic Meteorology; China Meteorological Press: Beijing, China, 2005; pp. $139-149$. (In Chinese)

2. Gao, S.T.; Tao, S.Y. The lower layer frontogenesis induced by the acceleration of the upper jet stream. Chin. J. Atmos. Sci. 1991, 15, 11-22. (In Chinese)

3. Yang, S.; Lau, K.M.; Kim, K.M. Variations of the East Asian jet stream and Asian-Pacific-American winter climate anomalies. J. Clim. 2002, 15, 306-325. [CrossRef]

4. Barton, N.P.; Ellis, A.W. Variability in wintertime position and strength of the North Pacific jet stream as represented by re-analysis data. Int. J. Climatol. 2009, 29, 851-862. [CrossRef]

5. Zhang, Y.C.; Wang, D.Q.; Ren, X.J. Seasonal variation of the meridional wind in the temperate jet stream and its relationship to the Asian monsoon. Acta Meteorol. Sin. 2008, 66, 707-715. (in Chinese).

6. Ren, X.J.; Yang, X.Q.; Chu, C.J. Seasonal variations of the synoptic scale transient eddy activity and polar front jet over East Asia. J. Clim. 2010, 23, 3222-3233. [CrossRef]

7. Koch, P.; Wernli, H.; Davies, H.C. An event-based jet-stream climatology and typology. Int. J. Climatol. 2006, 26, 283-301. [CrossRef]

8. Strong, C.; Davis, R.E. Variability in the altitude of fast upper tropospheric winds over the Northern Hemisphere. J. Geophys. Res. 2006, 111, D10106. [CrossRef]

9. Strong, C.; Davis, R.E. Winter jet stream trends over the Northern Hemisphere. Q. J. R. Meteorol. Soc. 2007, 133, 2109-2115. [CrossRef]

10. Archer, C.L.; Caldeira, K. Historical trends in the jet streams. Geophys. Res. Lett. 2008, 35, L08803. [CrossRef]

11. Strong, C.; Davis, R.E. Comment on "Historical trends in the jet streams" by Cristina L. Archer and Ken Caldeira. Geophys. Res. Lett. 2008, 35, L24806. [CrossRef]

12. Molnos, S.; Mamdouh, T.; Petri, S.; Nocke, T.; Weinkauf, T.; Coumou, C. A network-based detection scheme for the jet stream core. Earth Syst. Dyn. 2017, 8, 75-89. [CrossRef]

13. Chen, H.W.; Zhang, F.Q.; Alley, R.B. The robustness of midlatitude weather pattern changes due to Arctic sea ice loss. J. Clim. 2016, 29, 7831-7849. [CrossRef]

14. Thomas, N.; Nigam, S. Twentieth-century climate change over Africa: Seasonal hydroclimate trends and Sahara Desert expansion. J. Clim. 2018, 31, 3349-3370. [CrossRef]

15. Fan, K.; Xie, Z.M.; Wang, H.J.; Xu, Z.H.; Liu, J.P. Frequency of spring dust weather in North China linked to sea ice variability in the Barents Sea. Clim. Dyn. 2018, 51, 4439-4450. [CrossRef]

16. Kuang, X.Y.; Zhang, Y.C.; Liu, J. Seasonal variations of the East Asian subtropical westerly jet and the thermal mechanism. Acta Meteorol. Sin. 2007, 21, 192-203.

17. Dee, D.P.; Uppala, S.M.; Simmons, A.J.; Berrisford, P.; Poli, P.; Kobayashi, S.; Andrae, U.; Balmaseda, M.A.; Balsamo, G.; Bauer, P.; et al. The ERA-Interim reanalysis: Configuration and performance of the data assimilation system. Q. J. R. Meteorol. Soc. 2011, 137, 553-597. [CrossRef]

18. Adler, R.F.; Huffman, G.J.; Chang, A.; Ferraro, R.; Xie, P.P.; Janowiak, J.; Rudolf, B.; Schneider, U.; Curtis, S.; Bolvin, D.; et al. The version-2 Global Precipitation Climatology Project (GPCP) monthly precipitation analysis (1979-present). J. Hydrometeorol. 2003, 4, 1147-1167. [CrossRef]

19. Wang, N.; Jiang, D.; Lang, X. Northern westerlies during the Last Glacial Maximum: Results from CMIP5 simulations. J. Clim. 2018, 31, 1135-1153. [CrossRef]

20. Voigt, A.; Shaw, T.A. Impact of regional atmospheric cloud radiative changes on shifts of the extratropical jet stream in response to global warming. J. Clim. 2016, 29, 8399-8421. [CrossRef]

21. Hall, R.; Erdélyi, R.; Hanna, E.; Jones, J.M.; Scaife, A.A. Drivers of North Atlantic polar front jet stream variability. Int. J. Climatol. 2015, 35, 1697-1720. [CrossRef] 
22. Lee, S.; Kim, H.K. The dynamical relationship between subtropical and eddy-driven jets. J. Atmos. Sci. 2003, 60, 1490-1503. [CrossRef]

23. Faranda, D.; Sato, Y.; Messori, G.; Moloney, N.R.; Yiou, P. Minimal dynamical systems model of the northern hemisphere jet stream via embedding of climate data. Earth Syst. Dyn. 2018, 10, 555-567. [CrossRef]

(C) 2019 by the authors. Licensee MDPI, Basel, Switzerland. This article is an open access article distributed under the terms and conditions of the Creative Commons Attribution (CC BY) license (http://creativecommons.org/licenses/by/4.0/). 